\title{
Loss of capture late after right ventricular pacing lead revision: what is the mechanism?
}

\author{
Joachim Seegers $\cdot$ Lars Lüthje $\cdot$ Markus Zabel · \\ Dirk Vollmann
}

Received: 10 March 2009/Accepted: 28 May 2009/Published online: 25 June 2009

(c) The Author(s) 2009. This article is published with open access at Springerlink.com

\section{Case summary}

A 75-year-old woman was referred to our hospital because of dizziness and presumed pacemaker dysfunction (Fig. 1). Eight weeks earlier, the patient had underwent implantation of a single chamber pacemaker (Sensia, Medtronic, USA) with a tined, steroid-eluting bipolar right ventricular (RV) lead (4074 CapSure Sense, Medtronic, USA) for chronic atrial fibrillation and symptomatic bradyarrhythmia. Two weeks post-implantation surgical revision had been necessary due to RV lead dislocation. Device interrogation prior to hospital discharge had been inconspicuous with a RV pacing threshold less than $1.0 \mathrm{~V}$ at $0.4 \mathrm{~ms}$ during unipolar stimulation (Fig. 2), a pacing impedance of $612 \mathrm{Ohms}$ and an $\mathrm{R}$ wave amplitude sensing of $>22 \mathrm{mV}$. Chest X-ray suggested a regular lead position in the RV apex.

At presentation, the patient reported episodic dizziness and intermittent sharp left pectoral pain that was present since approximately 1 week. Intrinsic heart rate at rest was 50-60 bpm and blood pressure 130/85 $\mathrm{mmHg}$. The surface Electrocardiogram (ECG) showed unipolar pacing spikes without capture (Fig. 1). Device interrogation revealed a $\mathrm{RV}$ pacing threshold that had increased to $>6 \mathrm{~V}$ at $1 \mathrm{~ms}$ during unipolar stimulation, with a pacing impedance of $521 \mathrm{Ohms}$ and an R wave amplitude sensing of $>22 \mathrm{mV}$. During bipolar stimulation, a pacing threshold of $2.25 \mathrm{~V}$ at

\footnotetext{
J. Seegers $(\bowtie) \cdot$ L. Lüthje $\cdot$ M. Zabel · D. Vollmann Department of Cardiology, Clinical Electrophysiology, University Medical Center Goettingen,

Georg-August-Universitaet, Robert-Koch-Str. 40,

37075 Göttingen, Germany

e-mail: jseegers@med.uni-goettingen.de
}

$1.0 \mathrm{~ms}$ was measured, and the device was reprogrammed to bipolar pacing with an output of $4.5 \mathrm{~V}$ at $1.0 \mathrm{~ms}$ (Fig. 3). On the same day, however, continuos ECG monitoring on the ward revealed intermittent loss of capture (Fig. 4). Figure 5a shows the chest X-ray that was taken at the time the patient presented at our clinic. What is the most likely diagnosis?

\section{Commentary}

In patients with presumed pacemaker dysfunction, device interrogation should be performed first. In our case, device interrogation revealed dubious findings. We found excellent sensing parameters, an inconspicuous pacing impedance, unipolar exit block and bipolar capture with an elevated pacing threshold. In this situation, the comparison of a current chest X-ray with the image taken earlier after implantation may verify lead dislocation. In our case, no conclusions could be drawn from the post-implant X-ray due to a low image quality, but in consideration of the patient history, the current chest X-ray (Fig. 5a) was found to be suggestive for late lead perforation. This diagnosis was confirmed by native multidetector computed tomography (CT) of the chest (Fig. 6). CT imaging and echocardiography excluded significant pericardial effusion. Based on these findings, elective lead extraction was performed in the operating theatre with backup for emergency thoracotomy because of the elevated procedural risk for haemorrhagic pericardial effusion and tamponade. The lead could be removed without complications and a new RV lead (same model, 4074 CapSure Sense, Medtronic, USA) was implanted in the lower RV close to the apex. Postoperative device interrogation demonstrated a stable unipolar pacing threshold of $0.5 \mathrm{~V}$ at $0.5 \mathrm{~ms}$. 
Lead perforation is a rare complication in patients undergoing pacemaker implantation [1]. Acute perforation of the right ventricle has been reported in up to $1 \%$ of patients and is normally associated with haemorrhagic pericardial effusion and haemodynamic instability due to tamponade, necessitating pericardial drainage and occasionally surgical intervention [2,3]. Delayed lead perforation ( $\geq 1$ month after implantation) occurs in $0.1-0.8 \%$ of
Fig. 1 Surface ECG $(25 \mathrm{~mm} / \mathrm{s})$ taken at the general practitioner showing unipolar pacing spikes that are not followed by a QRS complex. Intrinsic heart rate $61 \mathrm{bpm}$, device programmed to VVI-R 60(-130) bpm, pacing rate $80 \mathrm{bpm}$

Fig. 2 Electrogram (EGM) printout from the pacing threshold measurement that was performed prior to hospital discharge $(25 \mathrm{~mm} / \mathrm{s}, 10 \mathrm{~mm} /$ $\mathrm{mV}$, the upper curve shows lead I and markers, the lower curve shows RV EGM): The right ventricular pacing threshold is smaller than $1.0 \mathrm{~V}$ at $0.4 \mathrm{~ms}$ during unipolar stimulation

Fig. 3 Effective right ventricular pacing after device reprogramming to bipolar stimulation with an output of $4.5 \mathrm{~V}$ at $1 \mathrm{~ms}(50 \mathrm{~mm} / \mathrm{s})$
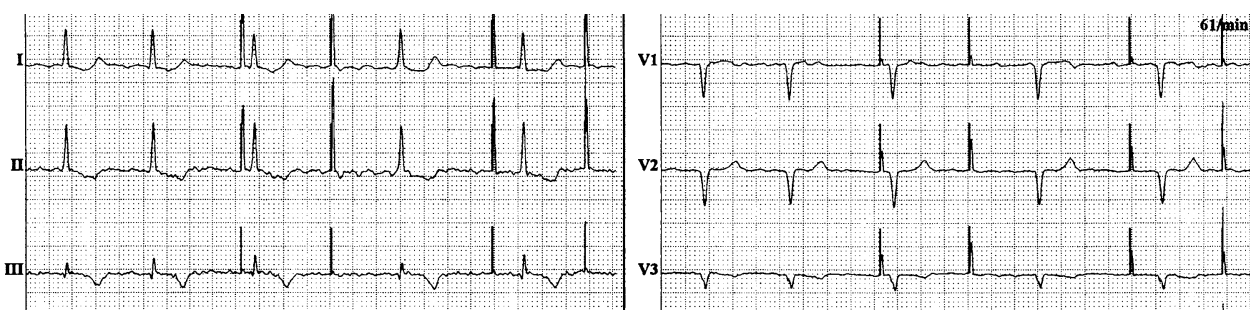

26.11 .0815 .0423

Schrittmachermodell: Medtronic Sensia SESR01 Seriennummer: NWR621481 Bericht Automatischer Reizschwellentest Software SW003 2.0 Copyright (c) Medtronic, Inc. 2005

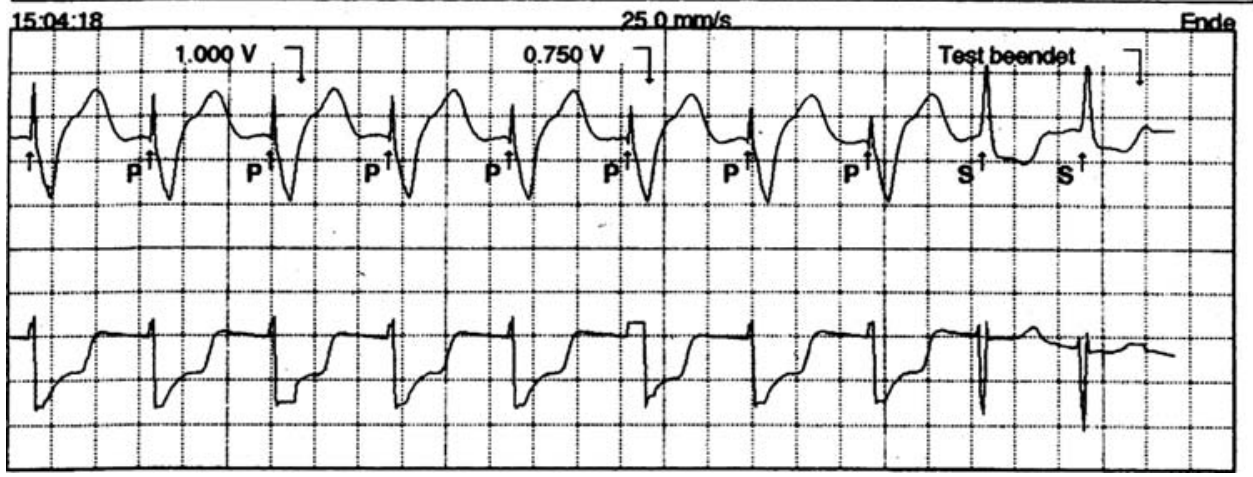

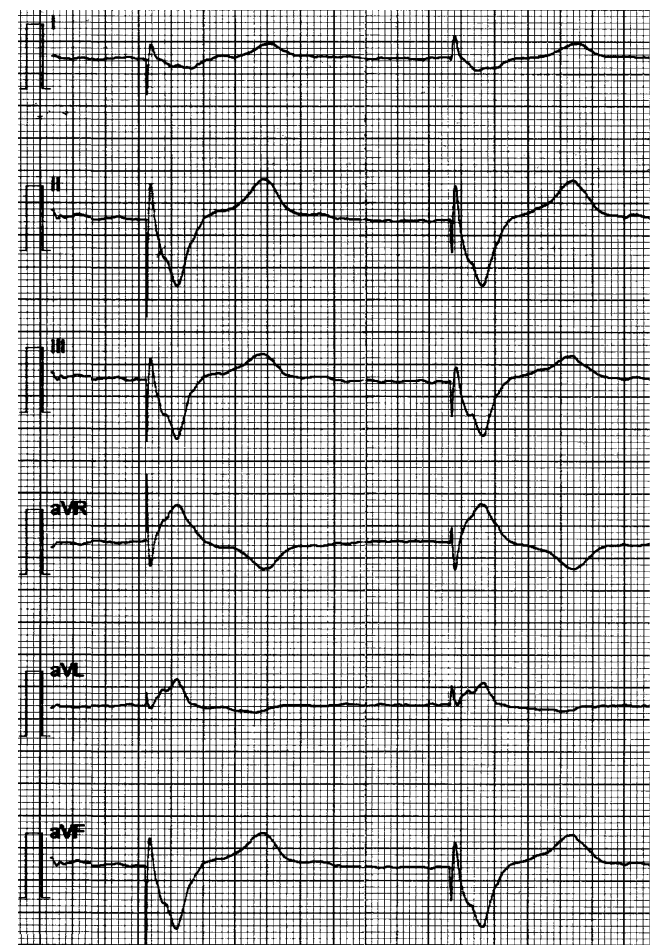

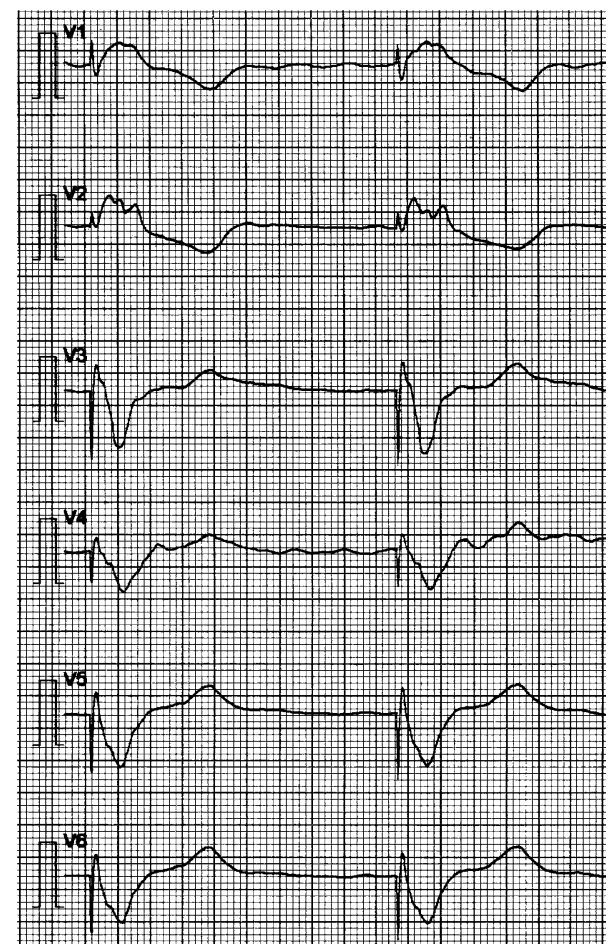




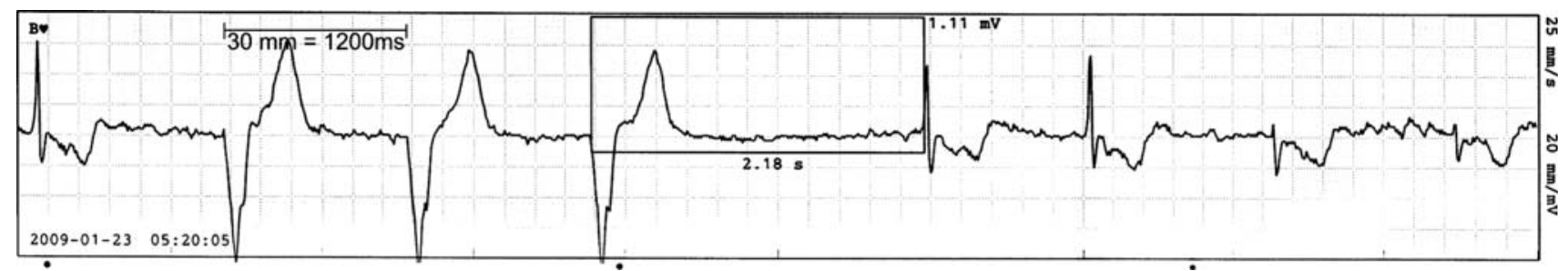

Fig. 4 ECG monitoring on the ward revealing intermittent loss of capture after reprogramming to bipolar right ventricular stimulation (VVI 50/min)

Fig. 5 a Posterior-anterior chest X-ray. Note the upwardly directed position of the lead tip on the left border of the heart shadow, suggesting lead perforation through the rightventricular apex. b Lateral chest $\mathrm{X}$-ray shows the lead towards the right ventricle

Fig. 6 Transversal (small image left) and oblique (large image) images from native multidetector computed tomography scan demonstrating cardiac perforation of the right ventricular lead (black and white arrows)
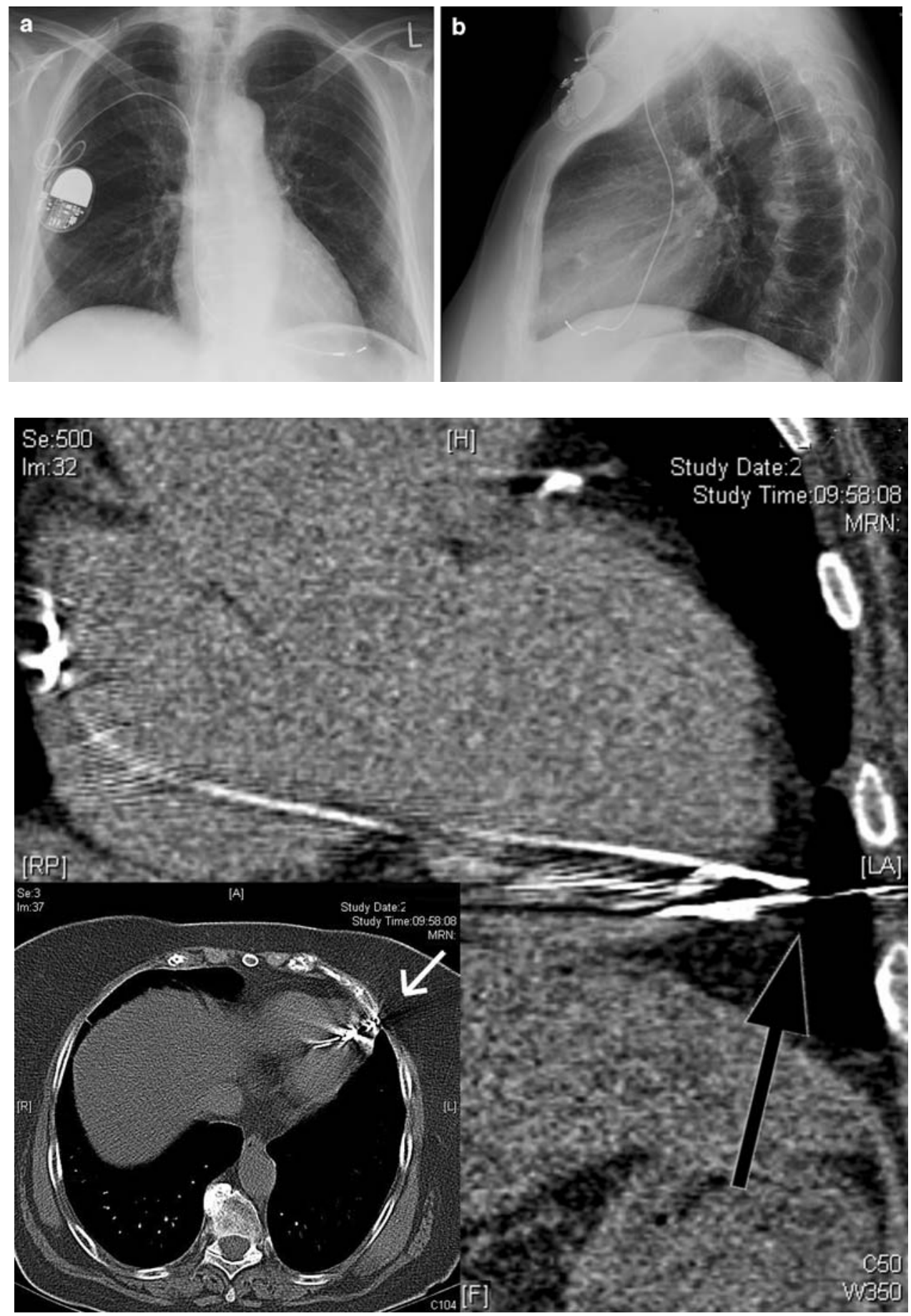
pacemaker implantations [4]. Rare cases of lead perforation later than 1 year have been reported [5].

Symptoms of late lead perforation are commonly subtle and unspecific $[6,7]$. Most commonly, this complication manifests with pacemaker malfunction such as insufficient cardiac stimulation and resulting symptoms such as dizziness (as in our case) or syncope [7]. Less frequently, late lead perforation may cause chest pain [3, 7, 8], hemopneumothorax [7, 9] and pneumothorax [7, 10]. Rare cases of cardiac tamponade or death have been documented in patients with late lead perforations [11]. On the other hand, completely asymptomatic cases of late lead perforation have also been described [12].

Conventional chest X-ray and transthoracic echocardiography can be helpful in diagnosis [8] but occasionally fail to identify lead perforation [12]. Multidetector CT has been shown to be a useful tool for verifying the diagnosis [13].

Several risk factors for lead perforation with symptomatic pericardial effusion after permanent pacemaker implantation are discussed: use of a temporary transvenous pacemaker, steroid use within 7 days prior to implant, use of helical screw ventricular leads, older age, body mass index $<20$ and longer fluoroscopy times [5, 14].

In our case, efficient pacing could at least transiently be achieved with the perforated lead by changing the pacing polarity from unipolar to bipolar. This observation suggests anodal stimulation from the RV lead ring [15], because CT scan illustrated that the perforated electrode tip was outside the myocardium and tip-ring spacing of Medtronic 4074 lead is $17 \mathrm{~mm}$. In the ECG that was taken during 'bipolar' stimulation with the perforated lead (Fig. 3), the precordial leads showed a right bundle branch block-like deformed QRS complex. This observation suggests left ventricular stimulation, but the lateral chest X-ray (Fig. 5b) excluded a left ventricular position of the pacing lead. Unfortunately, it remains speculative if the unusual QRS vector was an expression of anodal stimulation because no 12-lead surface ECG with effective ventricular stimulation was documented before the patient was referred to our institution.

In summary, late lead perforation should be considered if patients present with chest pain and pacemaker malfunction. The ability to capture the myocardium during bipolar but not during unipolar stimulation may be explained by a perforated electrode tip and resulting anodal stimulation.
Conflict of interest statement Zabel is Speaker's Bureau and Advisory Board of Medtronic, Vollmann is Lecturer for Medtronic.

Open Access This article is distributed under the terms of the Creative Commons Attribution Noncommercial License which permits any noncommercial use, distribution, and reproduction in any medium, provided the original author(s) and source are credited.

\section{References}

1. Kiviniemi MS, Pirnes MA, Eränen HJ et al (1999) Complications related to permanent pacemaker therapy. Pacing Clin Electrophysiol 22:711-720

2. Kron J, Herre J, Renfroe EG et al (2001) Lead and device-related complications in the antiarrhythmics versus implantable defibrillators trial. Am Heart J 141:92-98

3. Ellenbogen KA, Wood MA, Shepard RK (2002) Delayed complications following pacemaker implantation. Pacing Clin Electrophysiol 25:1155-1158

4. Khan MN, Joseph G, Khaykin Y et al (2005) Delayed lead perforation: a disturbing trend. Pacing Clin Electrophysiol 28:251253

5. Haq SA, Heitner JF, Lee L et al (2008) Late presentation of a lead perforation as a complication of permanent pacemaker insertion. Angiology 59:619-621

6. Akyol A, Aydin A, Erdinler I et al (2005) Late perforation of the heart, pericardium, and diaphragm by an active-fixation ventricular lead. Pacing Clin Electrophysiol 28:350-351

7. Asano M, Mishima A, Ishii T et al (1996) Surgical treatment for right ventricular perforation caused by transvenous pacing electrodes: a report of three cases. Surg Today 26:933-935

8. Laborderie J, Barandon L, Ploux S et al (2008) Management of subacute and delayed right ventricular perforation with a pacing or an implantable cardioverter-defibrillator lead. Am J Cardiol 102:1352-1355

9. Irwin JM, Greer GS, Lowe JE et al (1987) Atrial lead perforation: a case report. Pacing Clin Electrophysiol 10:1378-1381

10. Ho WJ, Kuo CT, Lin KH (1999) Right pneumothorax resulting from an endocardial screw-in atrial lead. Chest 116:1133-1134

11. Garcia-Bolao I, Teijeira R, Diaz-Dorronsoro I (2001) Late fatal right ventricular perforation as complication of permanent pacing leads. Pacing Clin Electrophysiol 24:1036-1037

12. Selcuk H, Selcuk MT, Maden O et al (2006) Uncomplicated heart and lung perforation by a displaced ventricular pacemaker lead: a case report. Pacing Clin Electrophysiol 29:429-430

13. Yavari A, Khawaja ZO, Krishnamoorthy S et al (2009) Perforation of right ventricular free wall by pacemaker lead detected by multidetector computed tomography. Europace 11:252-254

14. Mahapatra S, Bybee KA, Bunch TJ et al (2005) Incidence and predictors of cardiac perforation after permanent pacemaker insertion. Heart Rhythm 2:907-911

15. Occhetta E, Bortnik M, Marino P (2006) Ventricular capture by anodal pacemaker stimulation. Europace 8:385-387 